\title{
Sources, Effects, and Modelling of Interharmonics
}

\author{
Hsiung-Cheng Lin \\ Department of Electronic Engineering, National Chin-Yi University of Technology, No. 57, Sec. 2, Zhongshan Road, \\ Taiping District, Taichung 41170, Taiwan \\ Correspondence should be addressed to Hsiung-Cheng Lin; hclin@ncut.edu.tw
}

Received 21 February 2014; Accepted 29 March 2014; Published 5 May 2014

Academic Editor: Her-Terng Yau

Copyright (C) 2014 Hsiung-Cheng Lin. This is an open access article distributed under the Creative Commons Attribution License, which permits unrestricted use, distribution, and reproduction in any medium, provided the original work is properly cited.

Recently, the increasing use of power electronic systems and time-variant nonlinear loads has brought number of power harmonics/interharmonics, and the power supply quality is therefore seriously threatened. The presence of interharmonics strongly poses more difficulties in modelling and measuring the distorted waveforms. Therefore, this paper reviews the sources, effects, and modelling of interharmonics. It provides a variety of crucial phenomena caused by interharmonics. More importantly, it also gives a possible solution for engineers/researchers to use appropriate tools to measure interharmonics. Some methods with implementation results are introduced and discussed for details.

\section{Introduction}

The presence of power system interharmonics has not only brought many problems as harmonics but also produced additional problems. For instance, there are thermal effects, low frequency oscillation of mechanical system, light and CRT flicker, interference of control and protection signals, high frequency overload of passive parallel filter, telecommunication interference, acoustic disturbance, saturation of current transformer, subsynchronous oscillations, voltage fluctuations, malfunctioning of remote control system, erroneous firing of thyristor apparatus, the loss of useful life of induction motors, and so forth. These phenomena may even happen under low amplitude [1-5].

The leading methods referred to in the relevant literature for harmonic penetration studies can be classified as (a) direct current injection; (b) harmonic power flow; (c) iterative harmonic analysis; (d) experimental analog modeling; (e) time-domain modeling. In principle, it is very easy to include interharmonics in the classical model by the main concept of the Fourier fundamental periods [1]. Unfortunately, in practice, some concerns may still apply, being briefly concluded as follows. (1) The extension of low-power analog models and of time-domain models does have practical difficulties limit in the use of these models to cases of small system size. (2) The extension of the direct injection method is easy to obtain inaccurate results. (3) The extension of the harmonic power flow is very difficult in modeling nonlinear loads in the frequency domain when interharmonics are present. (4) The extension of the iterative harmonic analysis is quite complex in modelling the nonlinear loads [14].

\section{Sources of Interharmonics}

Basically, interharmonics types can be classified into two categories. The first type is that interharmonics are located around sidebands of the system frequency and harmonics due to a change of amplitude and/or phase caused by a rapid current variation of facilities. Actually, it is also the sources of power supply voltage fluctuation. The second type is asynchronous switching in static converters using semiconductor devices. It is the case that the switching frequency is not synchronised with the power system. Some major sources are discussed as follows.

(1) Variable-Load Electric Drives. Induction motors using stator and rotor sloting are one of the sources of interharmonics. When the motor is working at a constant speed, the interference frequency would occur between $500 \mathrm{~Hz}$ and $2000 \mathrm{~Hz}$. If it is during the acceleration period, the range would be larger. The motor which has nonsymmetrical characteristics, for example, rotor without accurate aim, will 


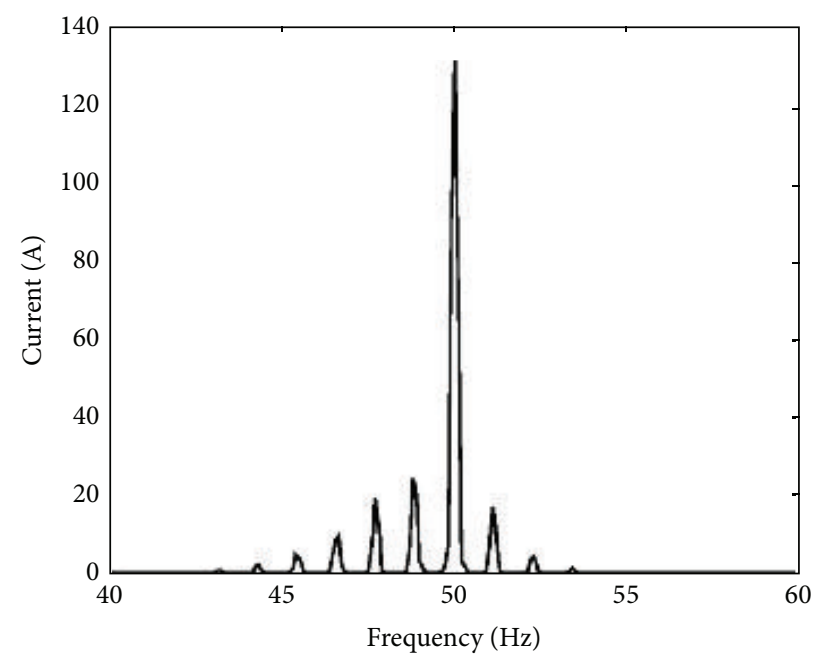

(a) Current spectrum

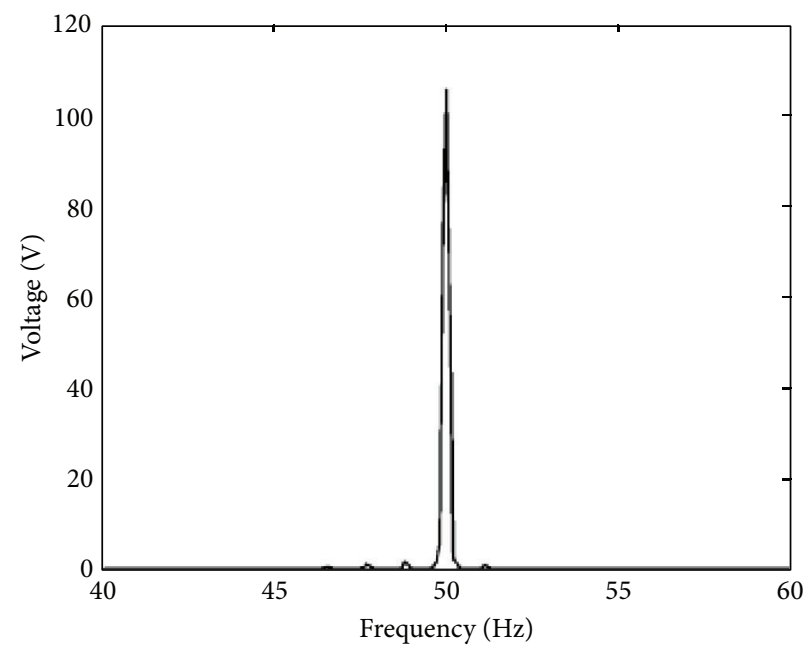

(c) Voltage spectrum

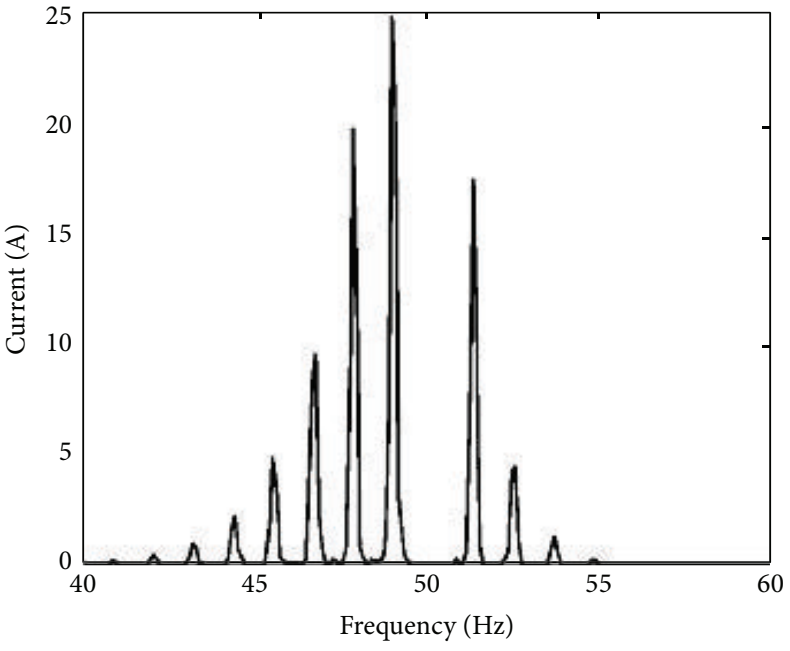

(b) Current spectrum

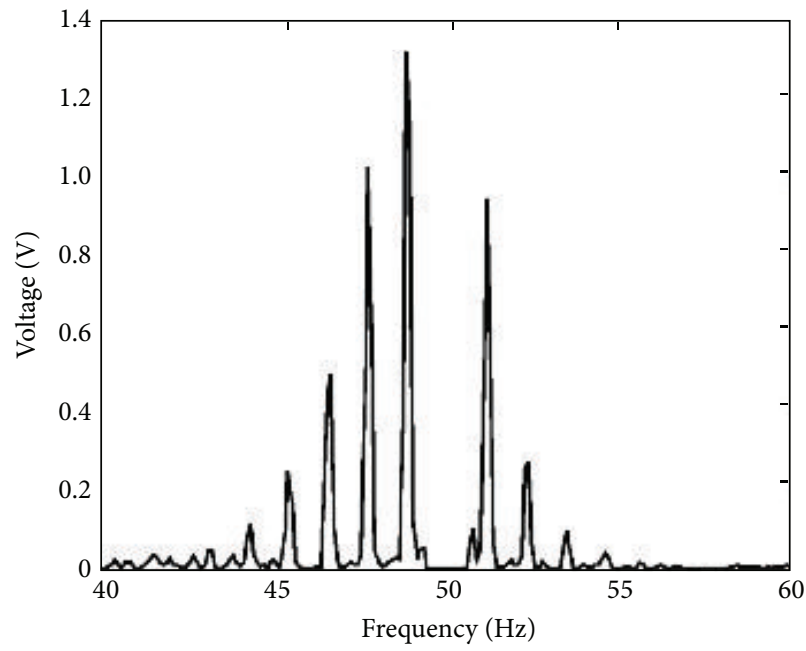

(d) Voltage spectrum

FIGURE 1: Spectrum of motor current and voltage: ((a), (c)) complete signal spectrum and ((b), (d)) spectrum removing fundamental component [6].

cause interharmonics. Figure 1 shows the spectrum of motor current and voltage [6]. Other cases are the drives adding variable-torque loads such as forge drives, forging hammers, automatic stamp machines, and electric saws.

(2) Double Conversion Systems. In power electronics facilities, it may be a source of interharmonics if the system contains a DC-link connecting two different AC systems. The classical examples are variable-speed motor, HVDC, other static frequency converters, and so forth. These systems generally contain both $\mathrm{AC} / \mathrm{DC}$ rectifier and DC/AC inverter, and DClink using reactor or capacitor is coupled between two sides. Ideal rectifier with infinite reactor or capacitor only generates characteristic harmonics as follows:

$$
f_{h}=\left(p_{1} n \pm 1\right) f
$$

where $p_{1}$ is the pulse number of rectifier, $n$ is integer, and $f$ is the system frequency.

In practice, the reactor or capacitor is finite so that DClink will consist of a series component, depending on the type of inverter, that is, current source inverter (CSI) and voltage source inverter (VSI) [7].

(a) CSI: the pulse number is $p_{2}$, and output frequency is $f_{o}$. The DC ripple will contain the following frequency:

$$
f_{r}=n p_{2} f_{o},
$$

where $n$ is integer.

(b) VSI: using synchronous PWM modulation, the DC ripple will contain the following frequency:

$$
f_{r}\left(m_{f}, j, r\right)=\left|m_{f} j \pm r\right| \cdot f_{o},
$$




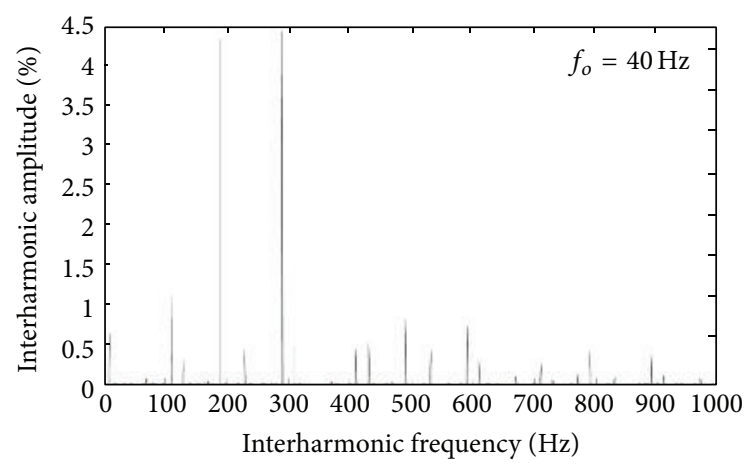

(a) CSI

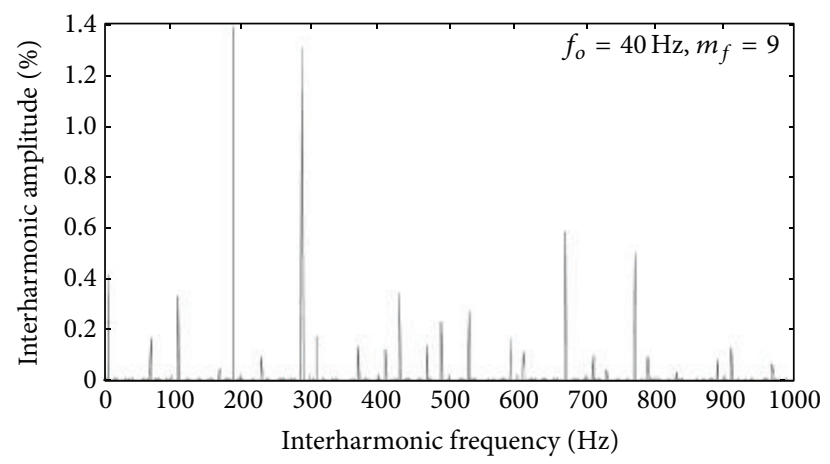

(b) PWM modulated VSI

Figure 2: Current interharmonics [7].

where $j$ and $r$ depend on the modulation ratio and $m_{f}$ is related to the switching method. In conclusion, the modulated source frequency is

$$
f_{i}=f_{h} \pm f_{r}
$$

Figure 2 indicates interharmonics visible from (a) CSI and (b) VSI, where $f=50 \mathrm{~Hz}$ and $f_{o}=40 \mathrm{~Hz}$ [7].

(3) Cycloconverters. Cycloconverters are one of the major interharmonics sources. They are widely applied in rolling mill, linear motor, drives, static-var generator, and so forth. The frequency of generated characteristic interharmonics is

$$
f_{i}=\left(p_{1} \cdot m \pm 1\right) f_{1} \pm p_{2} \cdot n \cdot f_{o},
$$

where $p_{1}=$ pulse number of rectifier and $p_{2}=$ output pulse number; $m, n=0,1,2,3, \ldots$ (integer number); $f_{o}=$ output frequency of cycloconverters.

Figure 3 shows the current interharmonics of typical cycloconverters with 6 pulses. Its output frequency is $5 \mathrm{~Hz}$ [8].

(4) Time-Varying Loads. Time-varying loads can generate interharmonics, including regular or irregular fluctuating loads. Typical regular time-varying loads are Welder machines, laser printer, integral cycle control instruments, and so forth. The produced interharmonics are dependent on the load frequency. Assume that the system voltage is $v(t)=\sin (2 \pi f t)$ and load is $R(t)=1-r \cos 2 \pi f_{o} t$, where

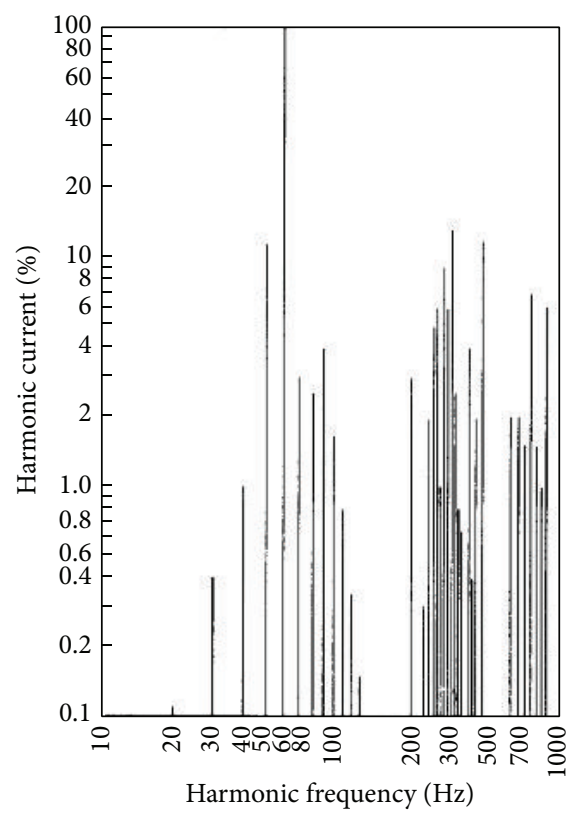

FIGURE 3: Current spectrum of typical cycloconverters $(60 \mathrm{~Hz})[8]$.

$r<1$ and $f_{o}$ is the load frequency. Therefore, the load current is

$$
\begin{aligned}
i(t)= & \frac{v(t)}{R(t)} \\
= & \frac{\sin (2 \pi f t)}{1-r \cos 2 \pi f_{o} t} \\
= & \sin (2 \pi f t) \\
& \times\left(1+r \cos 2 \pi f_{o} t+r^{2} \cos ^{2} 2 \pi f_{o} t+r^{3} \cos ^{3} 2 \pi f_{o} t+\cdots\right) .
\end{aligned}
$$

Extend (6), and it is found that interharmonics are involved such as $f \pm f_{o}, f \pm 2 f_{o}, f \pm 3 f_{o}, \ldots$. As can be seen, the current interharmonics are unvoidable if $f_{o}$ is not synchronized with $f$. The spectrum obtained from the laser printer is shown in Figure 4 [9].

Arc furnaces are examples of irregular time-varying loads. They have time-variant and nonlinear characteristics, covering both harmonics and interharmonics. Accordingly, they are very difficult to be modelled using mathematics equation. Figure 5 shows the current spectrum of arc furnace, where Figure 5(a) is AC-60 Hz system, and its interharmonics are concentrated on the surrounding of the system frequency. On the other hand, Figure 5(b) indicates that the most distinct interharmonics are located on the neighboring of harmonics for DC-50 Hz system [10].

(5) Wind Turbines. Wind turbines play a critical role in the interharmonics source due to the mechanical operation. During continuous operation with a constant speed, the variation of wind speed and tower shadow effect can cause a power line voltage fluctuation. Figure 6 shows the voltage spectrum (logarithm). The outcome is obtained from the 


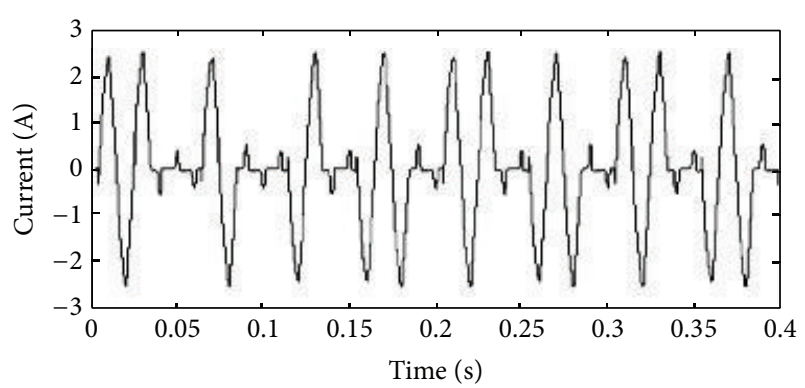

(a)

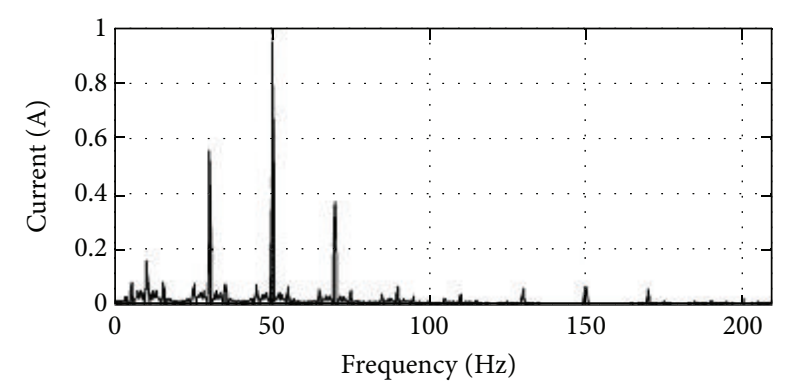

(b)

FIGURE 4: Laser printer current: (a) waveform, (b) spectrum [9].

analysis of time-domain model (solid line) and frequencydomain model (dotted line). The phenomenon comes from the mechanical torque oscillations. It is obvious that major interharmonics are focused on the fundamental frequency [11].

(6) Unexpected Sources. Nonlinear load itself cannot generate interharmonics. Some current interharmonics have the same frequency as the system voltage, but some of them result from interharmonics voltage modulation. Consequently, when interharmonics voltages appear, these components will become the source of interharmonics. Figure 7 reveals the rectifier current spectrum that is from $50 \mathrm{~Hz}$ voltage modulated with $1 \% 120 \mathrm{~Hz}$ interharmonic [9]. The outcome also shows special frequency couples (voltage and current), for example, $(20 \mathrm{~Hz}, 20 \mathrm{~Hz}),(20 \mathrm{~Hz}, 120 \mathrm{~Hz}),(120 \mathrm{~Hz}, 20 \mathrm{~Hz})$, and $(120 \mathrm{~Hz}, 120 \mathrm{~Hz})$. It exhibits that $20 \mathrm{~Hz}($ or $120 \mathrm{~Hz})$ interharmonic voltage can produce very high interharmonic current.

\section{Effects of Interharmonics}

The most effect by interharmonics is the light flicker problem. The system voltage may be disturbed as interharmonic voltage is beyond the limit tolerance, and thus light flicker may occur. Figure 8 shows the sensitive area of incandescent lamp. Note that the system frequency is $50 \mathrm{~Hz}$. This figure proves that the most sensitive area is located around the fundamental frequency, particularly at a lower frequency range [12].

The influence of RMS voltage of interharmonic on the voltage fluctuation is briefly discussed as follows.
Consider the power supply contains interharmonic components:

$$
v(t)=\sin \left(2 \pi f_{1} t\right)+a \sin \left(2 \pi f_{i} t\right),
$$

where $f_{1}$ is the power supply frequency, $f_{i}$ is the interharmonic frequency, and $a$ is the amplitude (p.u.) of interharmonic.

RMS voltage is defined as

$$
V=\sqrt{\frac{1}{T} \int_{0}^{T} v^{2}(t) d t}
$$

where $T\left(=1 / f_{1}\right)$ is the period.

Assume that interharmonic voltage has $0.2 \%$ deviation over the fundamental voltage. According to (7) and (8), we can obtain the result shown in Figure 9 [12]. It is found that the influence by the interharmonics of high frequency beyond twice of fundamental frequency is small. However, the interharmonics cannot be ignored for lower frequency components. Note that the system frequency is $50 \mathrm{~Hz}$.

\section{Modelling of Interharmonics}

4.1. DFT Method. By Fourier theory, any repetitive waveform can be extended to a series of sine waveforms in different frequencies. Harmonic is defined as a component of these waveforms. Its frequency is a multiple of fundamental frequency. For a distorted waveform $i_{s}(t)$, it can be represented as

$$
\begin{gathered}
i_{s}(t)=\sum_{k=-\infty}^{\infty} I_{s}\left(k \omega_{0}\right) e^{j k \omega_{0} t}, \\
I_{s}\left(k \omega_{0}\right)=\frac{1}{T} \int_{t}^{t+T} x(t) e^{-j k \omega_{0} t} d t,
\end{gathered}
$$

where $\omega_{0}(=2 \pi / T=2 \pi f)$ is the fundamental angular frequency and $I_{s}\left(k \omega_{0}\right)$ is the $k$ th coefficient.

$i_{s}(t)$ can be converted into a discrete signal $i_{s}[n]$. With discrete Fourier transform (DFT), it can be

$$
I_{s}[k]=\frac{1}{N} \sum_{n=0}^{N-1} i_{s}[n] W_{N}^{k n}
$$

where $I_{s}[k]$ is the magnitude of $i_{s}[n]$ at $f_{k}$ and $f_{k}=k / T$ and $W_{N}=\exp (j 2 \pi / N)$.

Inverting DFT can recover the original signal as

$$
i_{s}[n]=\sum_{k=0}^{N / 2-1} I_{s}[k] W_{N}^{-k n}
$$

Assume that $i_{s}[n]$ is periodical and its period is $T$. Fourier fundamental angular frequency $(\Delta \omega)$ is defined as

$$
\Delta \omega=\frac{2 \pi}{T} .
$$




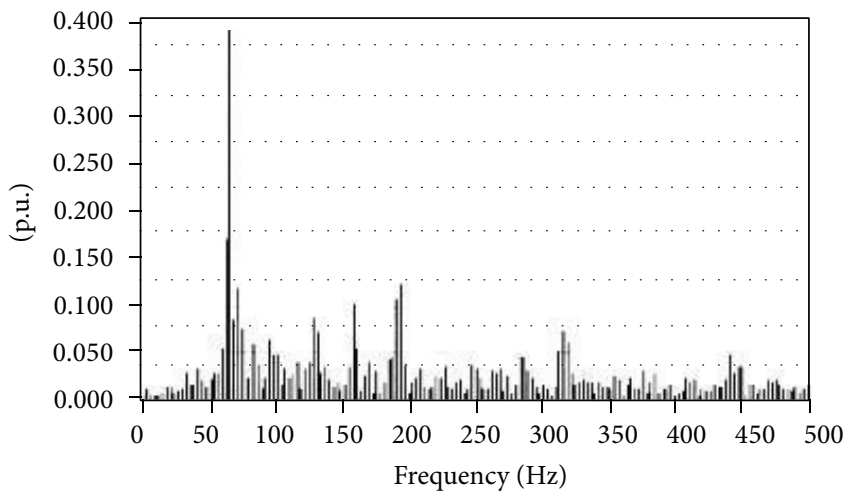

(a) AC-60 Hz system

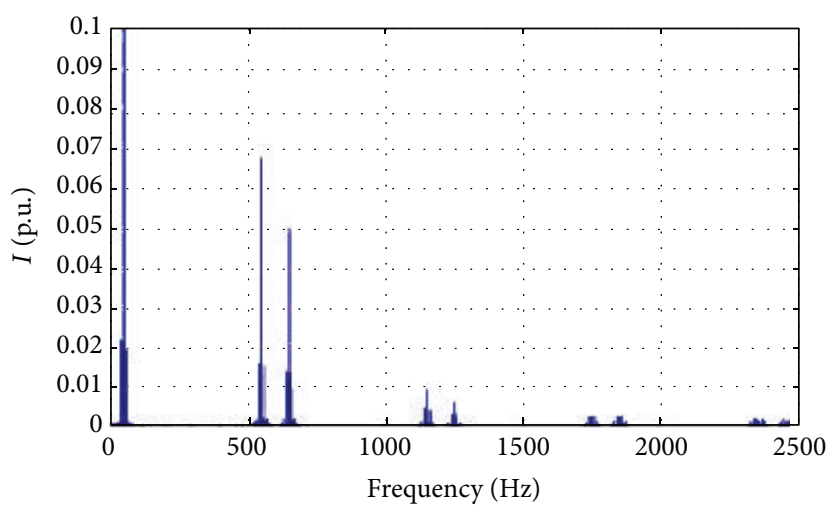

(b) DC-50 Hz system

Figure 5: Current spectrum of arc furnaces [10].

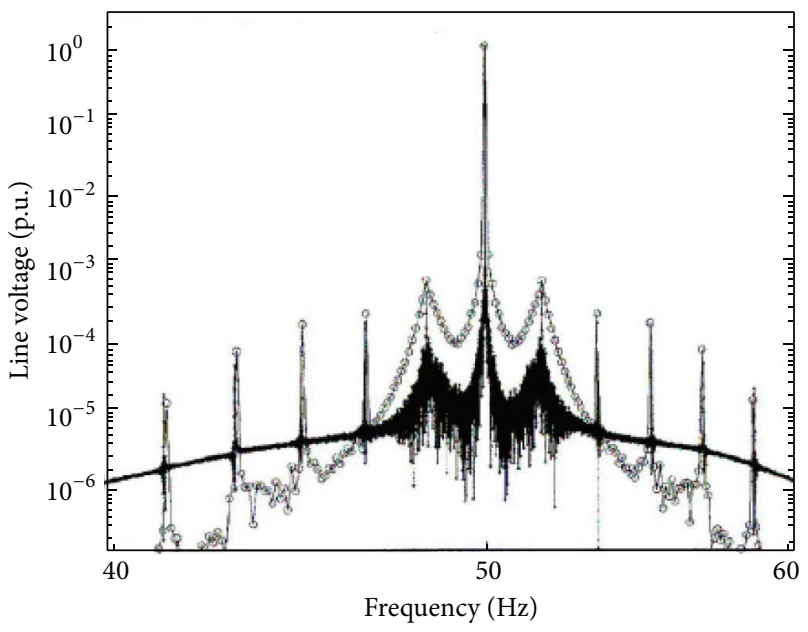

FIGURE 6: Voltage spectrum [11].

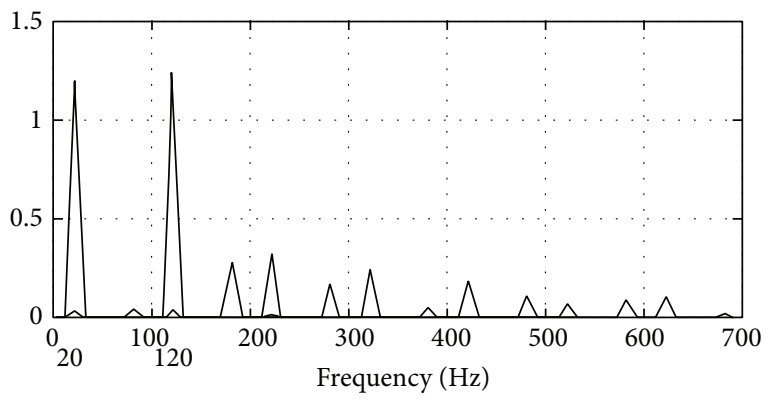

Figure 7: Rectifier current spectrum [9].

The sampling length is selected as $p$ periods ( $p>1$ with positive integer); $\Delta \omega$ can be rewritten as

$$
\Delta \omega=\frac{2 \pi}{p T}=\frac{\omega_{0}}{p} .
$$

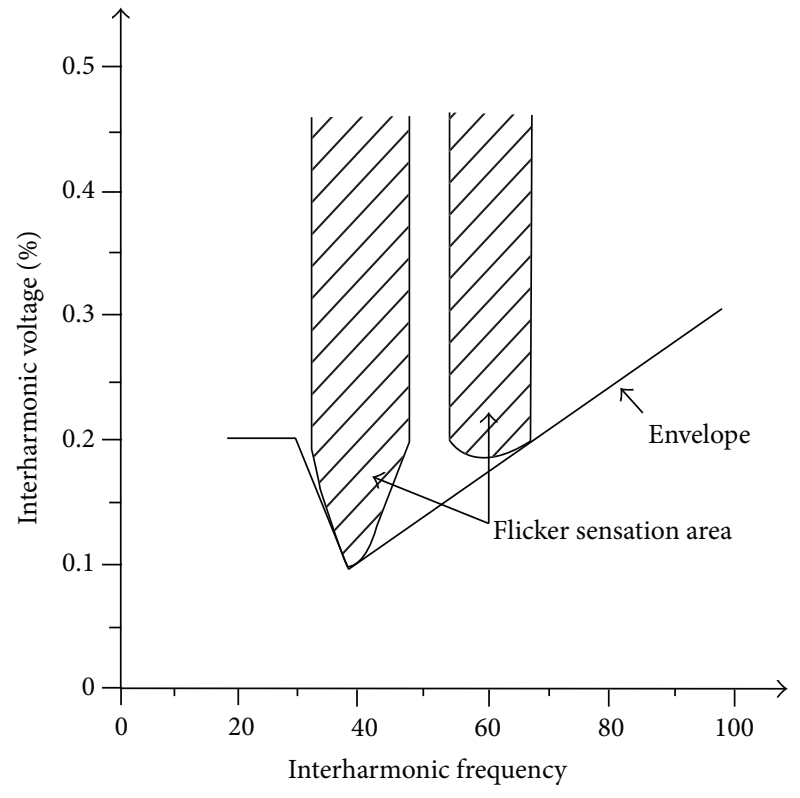

FIGURE 8: Sensitive flicker area of incandescent lamp [12].

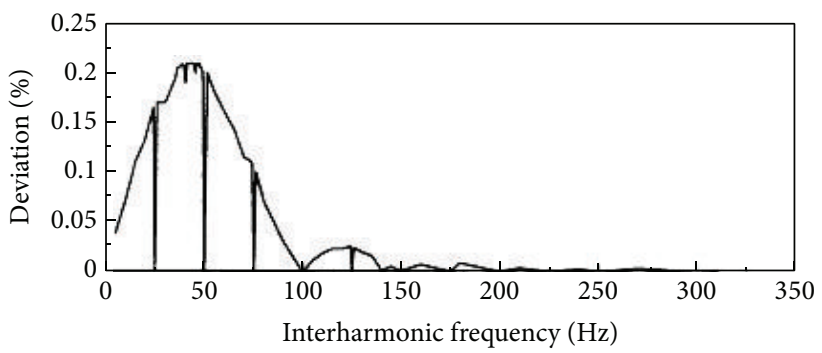

FIGURE 9: RMS voltage distortion with $0.2 \%$ deviation [12].

Therefore, Fourier fundamental frequency $(\Delta f)$ can be represented as

$$
\Delta f=\frac{1}{p T}=\frac{1}{p N_{s} T_{s}}=\frac{1}{N T_{s}}=\frac{f_{s}}{N},
$$

where $N_{s} \triangleq N / p$ and $T_{s} \triangleq 1 / f_{s}$. 


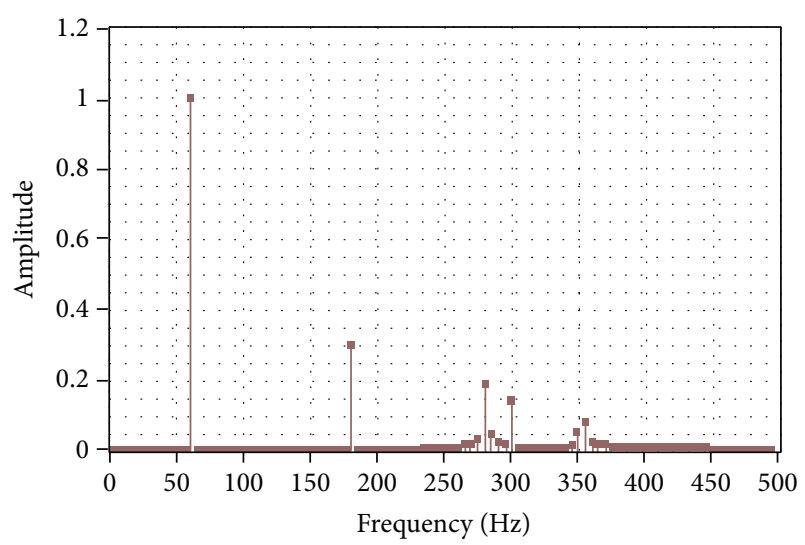

Figure 10: Spectrum analysis using DFT.

Figure 10 shows the waveform spectrum using DFT, where both $281 \mathrm{~Hz}$ and $353 \mathrm{~Hz}$ interharmonics are contained based on (15). Obviously, the DFT may obtain accurate harmonics spectrum but result in incorrect results for interharmonics analysis:

$$
\begin{aligned}
s(t)= & \sin (2 \pi \cdot 60 \cdot t)+0.3 \sin (2 \pi \cdot 180 \cdot t) \\
& +0.15 \sin (2 \pi \cdot 300 \cdot t)+0.2 \sin (2 \pi \cdot 281 \cdot t) \\
& +0.1 \sin (2 \pi \cdot 353 \cdot t) .
\end{aligned}
$$

4.2. IEC Grouping Method. IEC Standard suggested the interharmonics measurement method using the concept of "grouping" [13]. The principle is illustrated as the schematic diagram shown in Figure 11. Based on the Fourier analysis, the sampling window time is 10 periods for $50 \mathrm{~Hz}$ system. For $60 \mathrm{~Hz}$ system, 12 periods are required.

The definition of harmonic/interharmonic grouping is illustrated as follows.

(a) RMS Value of a Harmonic Group. Within the observation window, it is the square root of the sum of the amplitude squares of a harmonic and the spectral components adjacent to it. The energy contents of the neighbouring lines with that of the harmonic proper are summed as follows:

$$
G_{g, n+1}^{2}=\frac{C_{k-5}^{2}}{2}+\sum_{k=-4}^{4} C_{k+i}^{2}+\frac{C_{k+5}^{2}}{2} .
$$

(b) RMS Value of a Harmonic Subgroup. It is square root of the sum of the amplitude squares of a harmonic and the two spectral components immediately adjacent to it. The subgroup of output components of the DFT is to sum the energy contents of the frequency component directly adjacent to a harmonic on the harmonic proper:

$$
\begin{gathered}
G_{s g, n}^{2}=\sum_{k=-1}^{1} C_{k+i}^{2}, \\
G_{s g, n+2}^{2}=\sum_{k=-1}^{1} C_{k+i}^{2} .
\end{gathered}
$$

(c) RMS Value of an Interharmonic Group. It is square root of the sum of all interharmonics amplitude squares in the interval between two consecutive harmonic frequencies:

$$
C_{i g, n+1}^{9}=\sum_{i=1}^{9} C_{k+i}^{2} .
$$

(d) RMS Value of an Interharmonic Centred Subgroup. It is the RMS value of the squares of all interharmonics amplitudes in the interval between two consecutive harmonic frequencies, excluding frequency components directly adjacent to the harmonic frequencies:

$$
C_{i g, n}^{9}=\sum_{i=2}^{8} C_{k+i}^{2} .
$$

It is known that IEC method is a practical tool to measure interharmonics because it can reduce the effect of spectrum leakage, also disclosing the level of interharmonics. Only short sampling time $(200 \mathrm{~ms}, \Delta f=5 \mathrm{~Hz})$ required is another advantage. However, it has two limitations. (1) Spectrum leakage still exists. (2) It is unable to identify individual component (frequency and amplitude) so it is not suitable in system diagnostic purpose.

4.3. A Strategy of Leakage Energy Allocation (LEA) Method [15]. The power of the waveform, $P$, can be expressed by the Parseval relation in its discrete form [16] as

$$
P=\frac{1}{N} \sum_{n=0}^{N / 2-1} i_{s}[n]^{2}=\sum_{k=0}^{N / 2-1} I_{s}[k]^{2} .
$$
as

The power at the discrete frequency $f_{k}$ can be expressed

$$
P\left[f_{k}\right]=I_{s}[k]^{2}+I_{s}[N-k]^{2}=2 I_{s}[k]^{2},
$$

where $k=0,1,2, \ldots, N / 2-1$.

Therefore, the $m$ th harmonic amplitude at the frequency $f_{k}$ is expressed as

$$
A_{m}\left[f_{k}\right]=\sqrt{P\left[f_{k}\right]}=\sqrt{2} I_{s}[k]
$$

where $m=1,2, \ldots, M$.

The power of the $m$ th harmonic at $f_{k}$ may disperse over around the $f_{k}$ caused by the spectral leakage. By the concept of grouping, all spilled power within adjacent frequencies of 


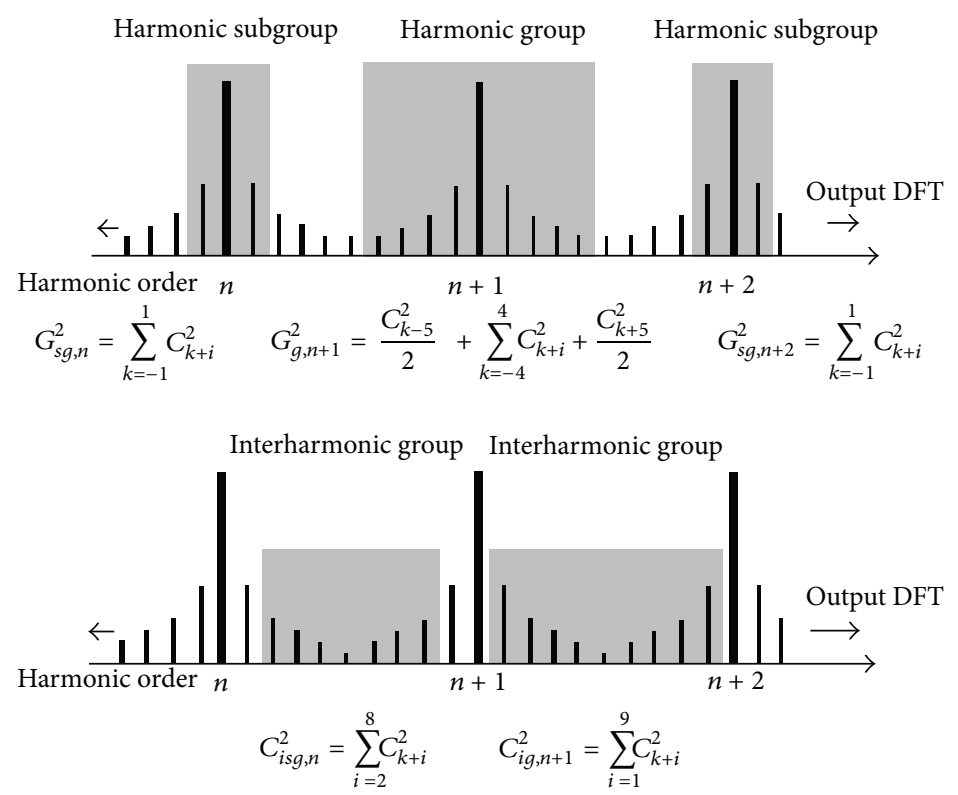

FIGURE 11: Depiction of harmonics/interharmonics [13].

harmonics can be restored into a "group power" [13]. In other words, each "group power," that is, $P_{m}^{*}\left[f_{k}\right]$, can be collected between $f_{k-\Delta k}$ and $f_{k+\Delta k}$ as follows:

$$
P_{m}^{*}\left[f_{k}\right]=\sum_{\Delta k=-\tau}^{+\tau}\left(A_{m}\left[f_{k+\Delta k}\right]\right)^{2},
$$

where $\tau$ is an integer number that denotes the group bandwidth.

Each harmonic amplitude can be calculated as

$$
A_{m}^{*}\left[f_{k}\right]=\sqrt{P_{m}^{*}\left[f_{k}\right]} .
$$

Figure 12 indicates the energy dispersing around the dominant component. Based on the empirical observation, the relation between sampling length and harmonic dispersed energy can be classified into two cases.

Case 1. The second stronger amplitude is found to be located at the right side of the dominant component, that is, $A_{m}\left[f_{k+1}\right]>A_{m}\left[f_{k-1}\right]$, due to overlong truncated-window length.

Case 2. The second stronger amplitude is located at the left side of the dominant component, that is, $A_{m}\left[f_{k+1}\right]<$ $A_{m}\left[f_{k-1}\right]$, due to insufficient truncated-window length. Based on the inductive method from empirical results, it is found that the frequency deviation amount has a relation in dispersed energy distribution [15]. Accordingly, the true frequency of interharmonic can be represented by the dominant frequency $\left(f_{k}\right)$ plus "frequency deviation" $\left(\Delta f_{k}\right)$, that is, $f_{k}+\Delta f_{k}$.

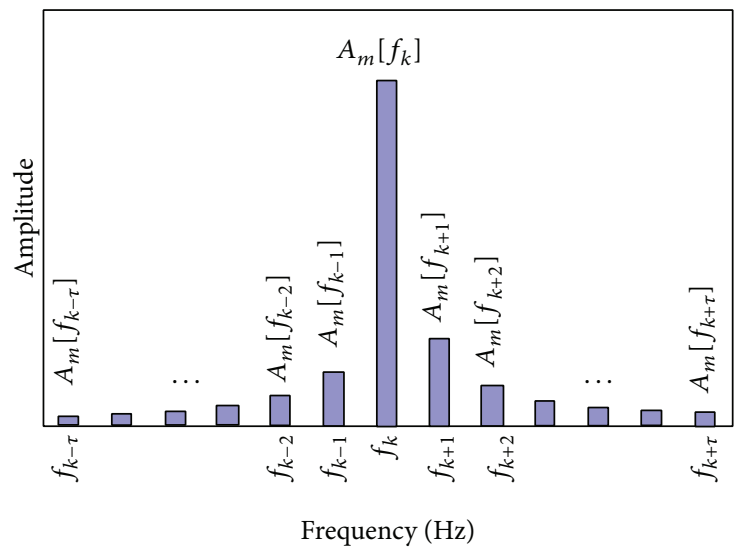

FIGURE 12: Energy dispersing around the dominant component.

The frequency deviation range (FDR) is defined as

$$
\Delta f_{k}=\frac{\sqrt{\sum_{\Delta k=1}^{+\tau} A_{m}\left[f_{k+\Delta k}\right]^{2}}}{\sqrt{\sum_{\Delta k=-\tau}^{0} A_{m}\left[f_{k+\Delta k}\right]^{2}}+\sqrt{\sum_{\Delta k=1}^{+\tau} A_{m}\left[f_{k+\Delta k}\right]^{2}}} \cdot \Delta f
$$

where $\Delta f$ is a factor of fundamental frequency, that is, $50 \mathrm{~Hz}$. It means that $\Delta f$ must be $1,2,5,10,25$, and 50 . 
According to the analysis of group-harmonic frequency deviation, the restored amplitude (RA) can be used for retrieving dispersed amplitude, defined as

$$
\mathrm{RA}=\sqrt{\sum_{\Delta k=-\tau}^{+\tau} A_{m}\left[f_{k+\Delta k}\right]^{2}}
$$

where $\tau=0,1,2,3, \ldots$.

The flowchart of the proposed LEA algorithm shown in Figure 13 is described briefly as follows.

(1) Set $f_{s}, N, \tau$.

(2) Sample power line waveform $i_{s}(t)$ using the sampling time $T_{f}$.

(3) Implement DFT.

(4) Set $m=1$ and determine the number $(M)$ of major harmonics/interharmonics.

(5) Determine the location of major frequency.

(6) Calculate $\Delta f_{k}$, RA.

(7) Find the frequency and amplitude of the $m$ th harmonic/interharmonic, that is, $f_{m}^{\prime}, A_{m}^{\prime}$.

(8) Let $m=m+1, M=M-1$.

(9) Go back to Step (6) until $M=0$. In other words, the procedure will continue until all major harmonics/interharmonics $\left(f_{m}^{\prime}, A_{m}^{\prime}\right)$ are found.

(10) Go back to Step (2) until the system is requested to stop.

Firstly, a waveform with fundamental frequency drift is considered [7, 8]. Equation (27) indicates that $i_{a}$ has $0.2 \mathrm{~Hz}$ drift at the fundamental frequency $\left(f_{1}\right)$. It also contains two interharmonics $\left(f_{2}\right.$ and $\left.f_{3}\right)$ :

$$
\begin{aligned}
i_{a}= & a_{1} \sin \left(2 \pi f_{1} t+\varphi_{1}\right)+a_{2} \sin \left(2 \pi f_{2} t+\varphi_{2}\right) \\
& +a_{3} \sin \left(2 \pi f_{3} t+\varphi_{3}\right),
\end{aligned}
$$

where $f_{1}=49.6 \mathrm{~Hz}$ is the fundamental (system) frequency with $0.2 \mathrm{~Hz}$ drift. The $f_{2}$ and $f_{3}$ are interharmonics that are $123 \mathrm{~Hz}$ and $327 \mathrm{~Hz}$, respectively. The $a_{1}=1.0, a_{2}=0.3$, and $a_{3}=0.15$ are their respective amplitudes. The $\varphi_{1}=0^{\circ}, \varphi_{2}=$ $12^{\circ}$, and $\varphi_{3}=35^{\circ}$ are their respective degrees.

In order to demonstrate the LEA method, an example using $\Delta f=1 \mathrm{~Hz}\left(f_{s}=1 \mathrm{kHz}, N=1000, T_{f}=1 \mathrm{sec}\right)$ and $\lambda=4$ is given as follows.

Spectrum of $i_{a}$ using $\Delta f=1 \mathrm{~Hz}$ is shown in Figure 14. As can be seen, the spectrum has serious spilled energy around the system frequency due to the frequency drift. On the other hand, the spectrums of $f_{2}$ and $f_{3}$ are correct. (a) System Frequency $f_{1}$. According to (25), the FDR beyond $49 \mathrm{~Hz}$ is calculated as

$$
\begin{aligned}
\Delta f_{k}= & \sqrt{0.75^{2}+0.21^{2}+0.12^{2}+0.086^{2}} \\
& \times\left(\sqrt{0.087^{2}+0.12^{2}+0.19^{2}+0.51^{2}}\right. \\
& \left.\quad+\sqrt{0.75^{2}+0.21^{2}+0.12^{2}+0.086^{2}}\right)^{-1} \cdot 1 \\
\approx & \frac{0.799}{0.564+0.799} \cdot 1 \approx 0.586 \cong 0.6 .
\end{aligned}
$$

As a result, $49 \mathrm{~Hz}\left(f_{k}\right)$ plus $0.6 \mathrm{~Hz}\left(\Delta f_{k}\right)$ is equal to $49.6 \mathrm{~Hz}$, matching the real value $\left(f_{1}=49.6 \mathrm{~Hz}\right)$.

According to (26), the restored amplitude is calculated as

$$
\begin{aligned}
\mathrm{RA}= & \left(0.087^{2}+0.12^{2}+0.19^{2}+0.51^{2}\right. \\
& \left.\quad+0.75^{2}+0.21^{2}+0.12^{2}+0.086^{2}\right)^{1 / 2} \\
\approx & 1.01 .
\end{aligned}
$$

Consequently, the RA is almost equal to 1.0, matching the real value $\left(a_{1}=1.0\right)$.

(b) Interharmonic $\left(f_{2}\right)$. The $f_{2}=123 \mathrm{~Hz}$ and $a_{2}=0.3$ can be obtained directly from DFT, matching the real values. In this case, no dispersed energy is found around the interharmonic $\left(f_{2}\right)$, and therefore it is not necessary for further process.

(c) Interharmonic $\left(f_{3}\right)$. Similarly, the $f_{3}=327 \mathrm{~Hz}$ and $a_{3}=0.15$ can be obtained directly from DFT, matching the real values. No dispersed energy is found around the interharmonic $\left(f_{3}\right)$, and therefore it is not necessary for further process.

Using different $\Delta f$ with $\lambda=4$, it can be concluded in Table 1. Obviously, DFT cannot give an accurate solution except $f_{2}$ and $f_{3}$ components using $\Delta f=1 \mathrm{~Hz}$. For the proposed LEA scheme, all components identification using $\Delta f=1,5$, and 10 can achieve a very correct value for either frequency or amplitude. On the other hand, $\Delta f$ using $25 \mathrm{~Hz}$ is unable to obtain a satisfactory result due to no remarkable adjacent dispersed energy. Actually, it is clear that the sampling time $\left(T_{f}\right)$ will be reduced if a large $\Delta f$ up to $10 \mathrm{~Hz}$ is chosen, not paying the cost of accuracy. However, in view of general practice, the risk of reciprocal interference between surrounding harmonics/interharmonics of spilled energy may arise once a larger $\Delta f$ is used. To reach a compromise, $\Delta f=5 \mathrm{~Hz}$ is taken into account in this study.

\section{Conclusions}

In recent years, the increasing generated power harmonics and interharmonics have caused serious power line pollution. For this reason, the research on harmonics and interhar- 


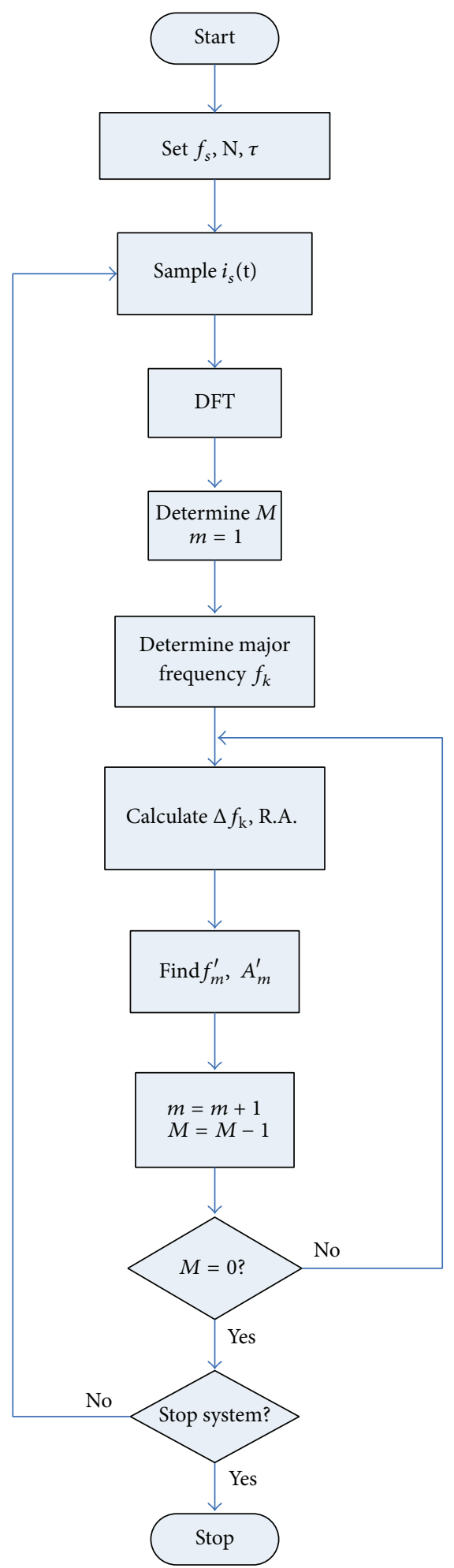

FIgURE 13: Flowchart of the LEA scheme.

monics is still a crucial task. Accordingly, this paper has reviewed major sources and effects of interharmonics. It has also illustrated how to apply DFT and IEC grouping methods in industry. A new leakage energy allocation (LEA) method is given for an alternative solution. It can recover all spilled leakage energy to obtain its original interharmonics amplitude. Also, every individual frequency component can be calculated using the principle of the distribution state of 
TABLE 1: Result comparison between DFT and LEA.

\begin{tabular}{|c|c|c|c|c|c|c|}
\hline \multirow{3}{*}{ Real values } & \multicolumn{6}{|c|}{$\Delta f$} \\
\hline & \multicolumn{2}{|c|}{$\Delta f=1 \mathrm{~Hz}$} & \multicolumn{2}{|c|}{$\Delta f=5 \mathrm{~Hz}$} & \multicolumn{2}{|c|}{$\Delta f=10 \mathrm{~Hz}$} \\
\hline & DFT & LEA & DFT & LEA & DFT & LEA \\
\hline$f_{1}=49.6(\mathrm{~Hz})$ & 49 & 49.6 & 45 & 49.5 & 40 & 49.5 \\
\hline$a_{1}=1.0$ & 1.0 & 1.01 & 0.99 & 1.00 & 1.0 & 1.02 \\
\hline$f_{2}=123(\mathrm{~Hz})$ & 123 & 123 & 120 & 123 & 120 & 123 \\
\hline$a_{2}=0.3$ & 0.3 & 0.3 & 0.22 & 0.29 & 0.26 & 0.29 \\
\hline$f_{3}=327(\mathrm{~Hz})$ & 327 & 327 & 325 & 327 & 320 & 327 \\
\hline$a_{3}=0.15$ & 0.15 & 0.15 & 0.076 & 0.146 & 0.13 & 0.148 \\
\hline
\end{tabular}

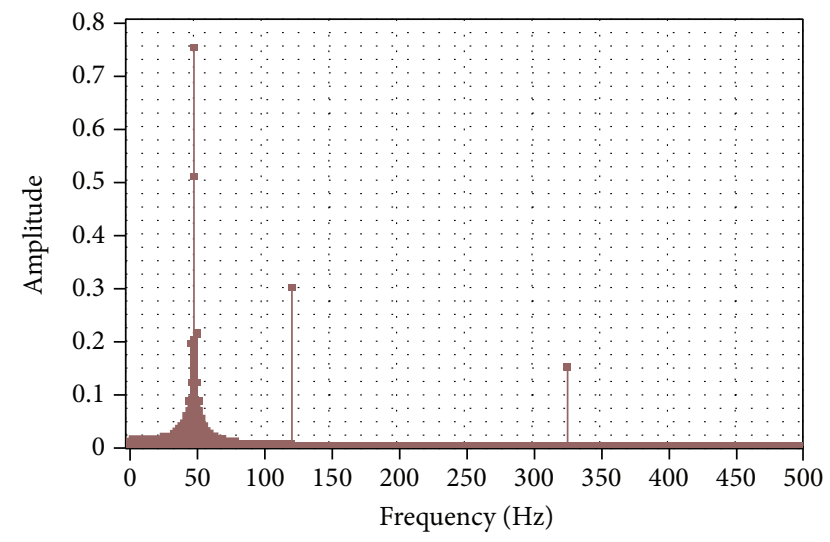

FIGURE 14: Spectrum of $i_{a}$ using $\Delta f=1 \mathrm{~Hz}$.

spilled leakage energy. Its implementation results prove that the proposed LEA approach is feasible in terms of rapid and high-precision performance.

\section{Conflict of Interests}

The author declares that there is no conflict of interests regarding the publication of this paper.

\section{References}

[1] H. C. Lin, "Accurate harmonic/inter-harmonic estimation using DFT-based Group-harmonics energy diffusion algorithm," Canadian Journal of Electrical and Computer Engineering, vol. 36, no. 4, pp. 158-171, 2014.

[2] D. Gallo, R. Langella, and A. Testa, "Inter-harmonics. Part 1. Aspects related to modeling and simulation," in Proceedings of the 6th International Workshop on Power Definitions and Measurements under Non-Sinusoidal Conditions, pp. 168-173, Milan, Italy, October 2003.

[3] D. Gallo, R. Langella, and A. Testa, "Inter-harmonics. Part 2. Aspects related to measurement and limits," in Proceedings of the 6th International Workshop on Power Definitions and Measurements under Non-Sinusoidal Conditions, pp. 174-181, Milano, Italy, October 2003.

[4] J. Barros, E. Pérez, A. Pigazo, and R. I. Diego, "Simultaneous measurement of harmonics, interharmonics and flicker in a power system for power quality analysis," in Proceedings of the 5th International Conference on Power System Management and Control, pp. 100-105, April 2002.

[5] M. Karimi-Ghartemani and M. R. Iravani, "Measurement of harmonics/inter-harmonics of time-varying frequencies," IEEE Transactions on Power Delivery, vol. 20, no. 1, pp. 23-31, 2005.

[6] Z. Hanzelka and A. Bien, Harmonics, Interharmonics, AGH University of Science and Technology, 2004.

[7] A. Testa, M. F. Akram, R. Burch et al., "Interharmonics: theory and modeling," IEEE Transactions on Power Delivery, vol. 22, no. 4, pp. 2335-2348, 2007.

[8] Interharmonics in Power Systems, IEEE Interharmonic Task Force, Cigré 36. 05/CIRED 2 CC02 Voltage Quality Working Group.

[9] D. Gallo, R. Langella, and A. Testa, "Desynchronized processing technique for harmonic and interharmonic analysis," IEEE Transactions on Power Delivery, vol. 19, no. 3, pp. 993-1001, 2004.

[10] C. Vilar, J. Usaola, and H. Amarís, "A frequency domain approach to wind turbines for flicker analysis," IEEE Transactions on Energy Conversion, vol. 18, no. 2, pp. 335-341, 2003.

[11] R. Carbone, A. lo Schiavo, P. Marino, and A. Testa, "Frequency coupling matrices for multi-stage conversion system analysis," European Transactions on Electrical Power, vol. 12, no. 1, pp. 1724, 2002.

[12] Interharmonics in Power Systems, IEEE Interharmonic Task Force, Cigré 36. 05/CIRED 2 CC02 Voltage Quality Working Group.

[13] Z. Hanzelka and A. Bien, Power Quality Application Guide, AGH University of Science and Technology, 2004.

[14] R. Carbone, D. Menniti, R. E. Morrison, and A. Testa, "Harmonic and interharmonic distortion modeling in multiconverter systems," IEEE Transactions on Power Delivery, vol. 10, no. 3, pp. 1685-1692, 1995.

[15] H. C. Lin, "Inter-harmonic identification using groupharmonic weighting approach based on the FFT," IEEE Transactions on Power Electronics, vol. 23, no. 3, pp. 1309-1319, 2008.

[16] IEC, 61000-4-7: 2002 Electromagnetic compatibility (EMC) Part 4. Testing and measurement techniques Section 7: general guide on harmonics and interharmonics measurements and instrumentation for power supply systems and equipment connected thereto. 


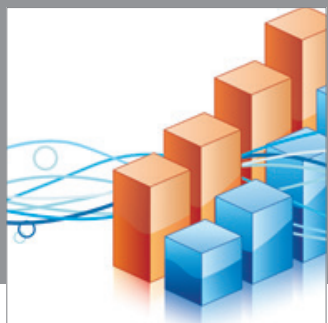

Advances in

Operations Research

mansans

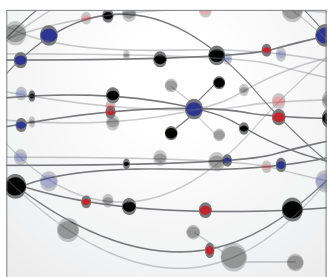

The Scientific World Journal
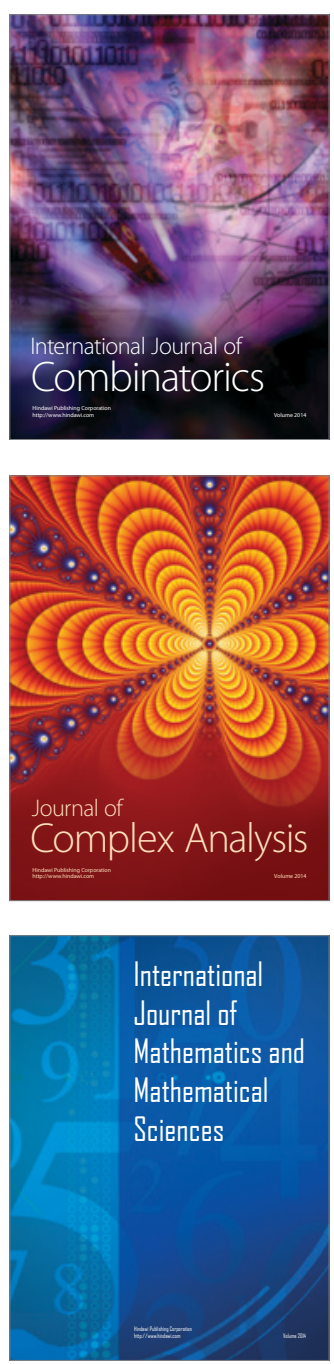
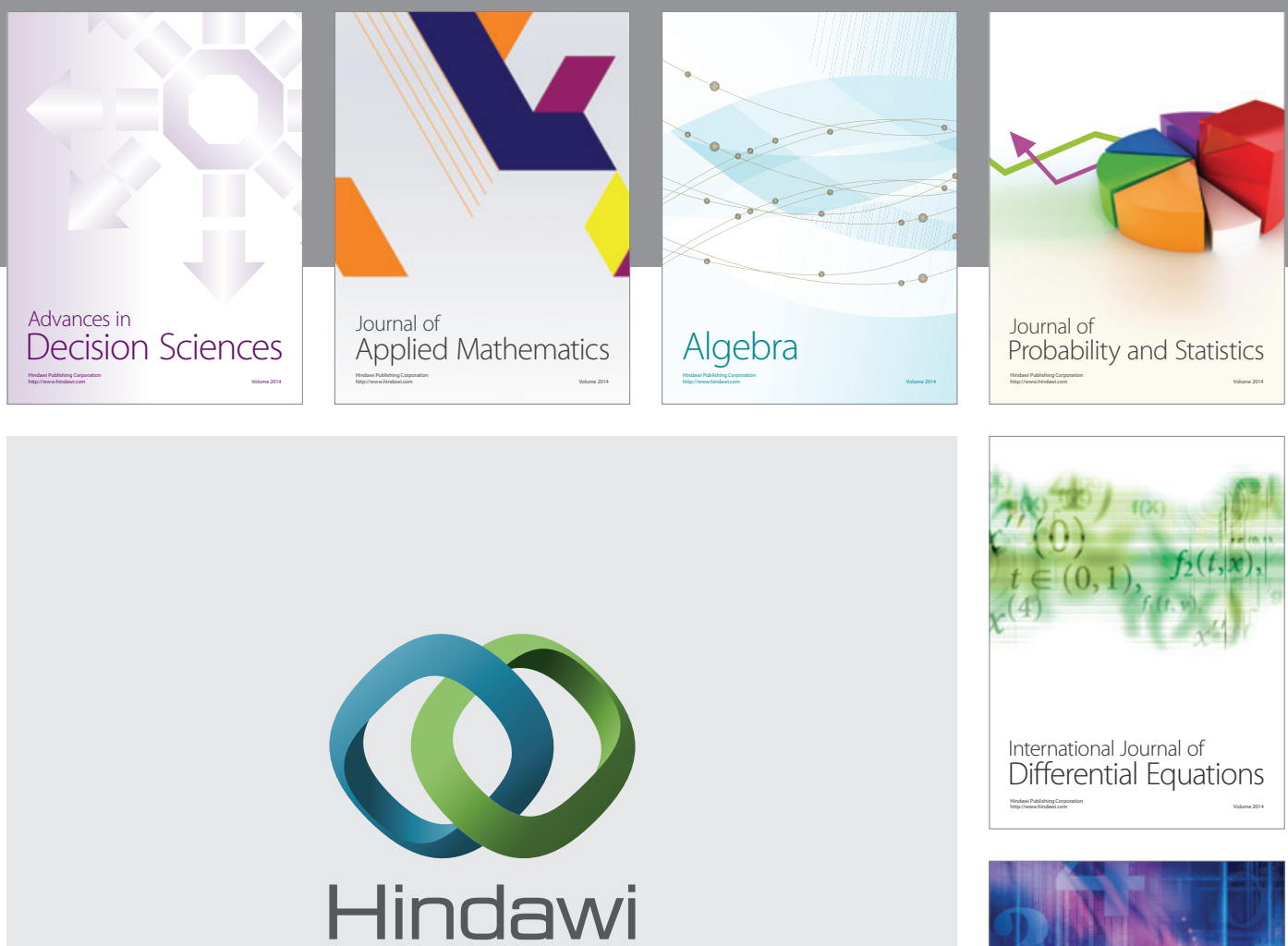

Submit your manuscripts at http://www.hindawi.com
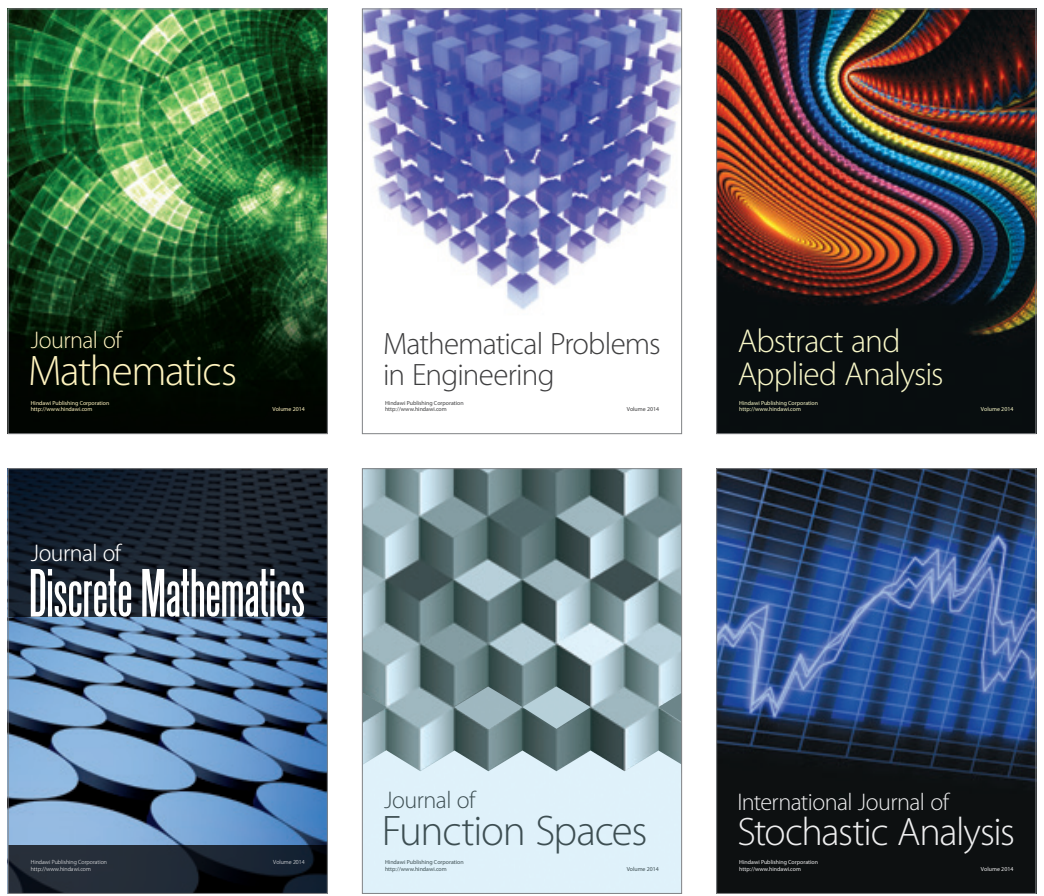

Journal of

Function Spaces

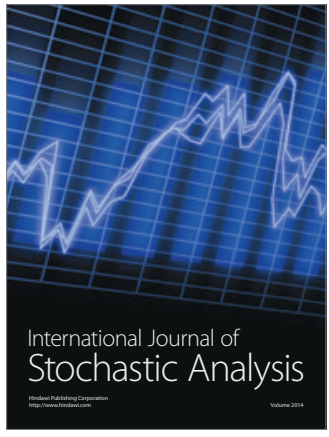

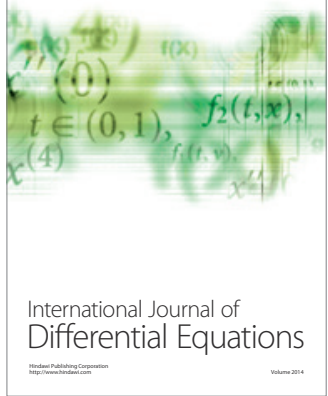
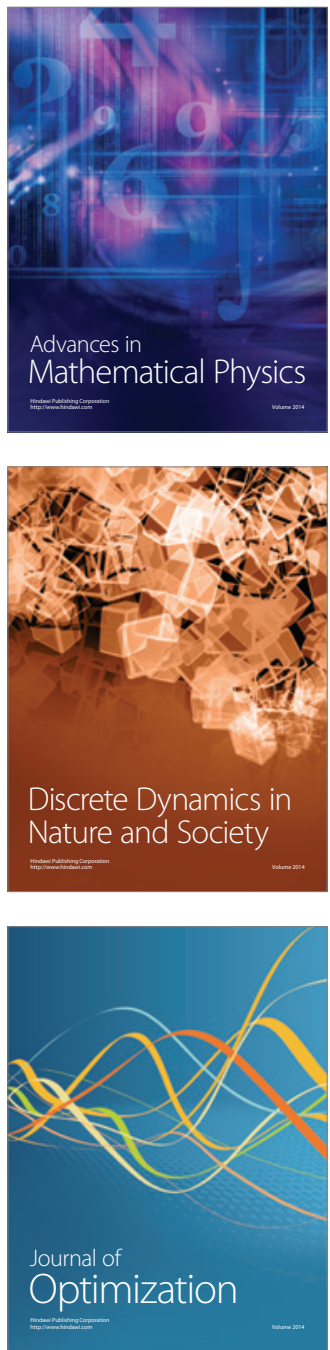